\title{
A Unified Anti-Windup Technique for Fuzzy and Sliding Mode Controllers
}

\author{
R.-E. Precup, M.L. Tomescu, E.M. Petriu
}

\author{
Radu-Emil Precup* \\ Politehnica University of Timişoara \\ Department of Automation and Applied Informatics \\ Bd. V. Parvan 2, 300223 Timisoara, Romania \\ *Correspondig author: radu.precup@upt.ro
}

\section{Marius L. Tomescu}

Aurel Vlaicu University of Arad

Faculty of Computer Science

Complex Universitar M, Str. Elena Dragoi 2, 310330 Arad, Romania

E-mail: tom_uav@yahoo.com

\section{Emil M. Petriu}

University of Ottawa

School of Electrical Engineering and Computer Science

800 King Edward, Ottawa, ON, K1N 6N5 Canada

E-mail: petriu@uottawa.ca

\begin{abstract}
This paper proposes the unified treatment of an anti-windup technique for fuzzy and sliding mode controllers. A back-calculation and tracking anti-windup scheme is proposed in order to prevent the zero error integrator wind-up in the structures of state feedback fuzzy controllers and sliding mode controllers. The state feedback sliding mode controllers are based on the state feedback-based computation of the switching variable. An example that copes with the position control of an electro-hydraulic servo-system is presented. The conclusions are pointed out on the basis of digital simulation results for the state feedback fuzzy controller.

Keywords: Anti-windup technique, electro-hydraulic servo-system, fuzzy control, saturation, sliding mode control, digital simulation.
\end{abstract}

\section{Introduction}

There are many situations in industrial control applications when a mismatch between the control signal (controller output) and the input of the process occurs. The saturation of controller output due to the functionality of the controller is such a natural process. The anti-windup techniques correct the controller output in the case of controllers with integral (I) component, but other components of the controllers can cause the saturation. Some discussions on the strong or weak impacts of the integrator wind-up and of saturation are presented in [1-5].

The anti-windup is applied to nonlinear systems including sliding mode control systems and fuzzy control systems, with representative examples given in [6-9]. A static anti-windup compensator for linear sliding mode controllers is designed in [10] on the basis of Linear Matrix Inequality (LMI) conditions derived from Lyapunov stability and L2-gain performance. The switching function of sliding mode controllers is modified in [11] to reduce the discontinuous component of the control signal during saturation. An adaptive anti-windup PID sliding mode scheme is proposed in [12]. The sliding surface for robust saturated sliding mode control is designed in [13] as a problem of root clustering. A dead-zone technique is employed in [9] in the framework of adaptive sliding mode control combined with fuzzy logic. The necessity of anti-windup measures in fuzzy 
control is pointed out in [14] and focused on Mamdani proportional-integral-fuzzy controllers. The fuzzy models of nonlinear models are involved in [15] in the design of piecewise fuzzy antiwindup dynamic output feedback controllers based on piecewise quadratic Lyapunov functions. Starting with a stabilizing dynamic output feedback fuzzy controller, an anti-windup block is designed in [16] to maximize the size of estimate of the domain of attraction, and sufficient Lyapunov-Krasovskii stability conditions are derived.

This paper suggests the application of a back-calculation and tracking anti-windup scheme to the zero error integrator in the framework of state feedback fuzzy controllers and state feedback sliding mode controllers. The specific feature of state feedback sliding mode controllers is the state feedback-based computation of the switching variable. The paper is supported by our previous results in fuzzy control [17-24], and proposes the unified treatment of anti-windup techniques in fuzzy and sliding mode controllers. This leads to good effects on the overall control system performance. The expression of the parameters of the anti-windup block is given, but these parameters can be optimized in terms of, for example, the optimal tuning of the anti-windup tracking gain carried out in [25].

This paper represents a step forward in the systematic design of fuzzy control systems, pointed out by Prof. Zadeh in [26] and [27]. The mathematics of fuzzy sets must be incorporated in the structure of fuzzy controllers by appropriate operators and parameters [28-30,32,32-34]. The model-based design using fuzzy models is emphasized in [35-45], but neural networks are used in [46-48]. This paper also represents a step forward in the systematic design of sliding mode control systems in the context of other popular techniques [49-53]. The parameters of both fuzzy and sliding mode controllers can be optimally tuned by means of appropriate optimization problems and algorithms [54-58].

The paper is organized as follows: Section 2 is dedicated to the modeling of state feedback sliding mode and fuzzy control systems. The proposed back-calculation and tracking anti-windup scheme is presented in Section 3. Section 4 applies the scheme to the position control of an electro-hydraulic servo-system and simulation results are included. The conclusions are outlined in Section 5.

\section{Models of State Feedback Sliding Mode and Fuzzy Control Sys- tems}

The unified structure of state feedback sliding mode and fuzzy control systems is presented in Figure 1, where: $w$ - the reference input, $v$ - the disturbance input, $u$ - the control signal, $y$ - the controlled output, $e=w=y$ - the control error, $\mathbf{x}_{p}$ - the state vector of the process $\mathrm{P}$, supposed to be observable and controllable, $\mathbf{x}_{p} \in \mathbf{R}^{n}$, ZEI - the zero error integrator (to obtain the zero steady-state value of the control error), $x_{R}$ - the nominal integrator output, $x_{R L^{-}}$ the saturated (limited) integrator output, RB - the reference block, SB - the switching block, $g$ - the switching variable, $\left\{k_{R}, k_{w}, T_{i}, u_{0}, \mathbf{k}_{p}^{T}\right\}$ - the parameters of the sliding mode controller (SMC), $T$ stands for matrix transposition, $\mathbf{k}_{p}^{T} \in \mathbf{R}^{1 \times n},\left\{-x_{L}, x_{L}\right\}$ - the limits of the saturation element that belongs to ZEI, $x_{L}=$ const $>0$. The structure given in Figure 1 is obtained by the appropriate transformation and extension of the sliding mode control scheme presented in [59], the abbreviation FC indicates the fuzzy controller, and the detailed structure of SMC is illustrated in the lower part of Figure 1. Both controllers are presented as nonlinear blocks in Figure 1.

The $\mathrm{P}$ in the SMC is described by the $n^{\text {th }}$ order state-space model: 


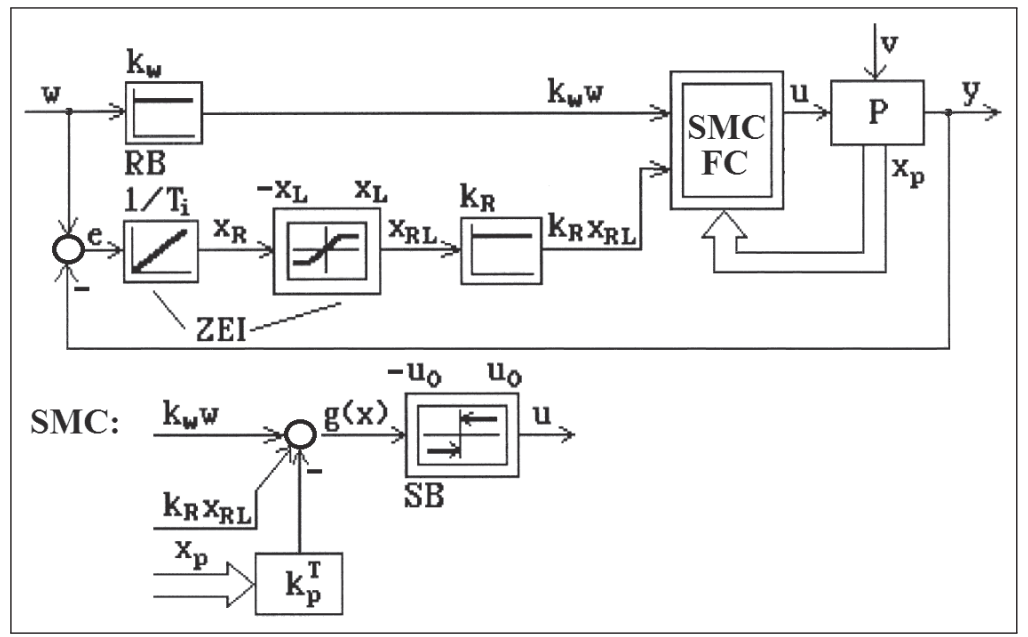

Figure 1: Unified structure of state feedback sliding mode and fuzzy control systems.

$$
\begin{aligned}
\dot{\mathbf{x}}_{p} & =\mathbf{A}_{p} \mathbf{x}_{p}+\mathbf{b}_{p} u+\mathbf{b}_{p v} v, \\
y & =\mathbf{c}_{p}^{T} \mathbf{x}_{p},
\end{aligned}
$$

where $\mathbf{A}_{p} \in \mathbf{R}^{n \times n}, \mathbf{b}_{p} \in \mathbf{R}^{n \times 1}, \mathbf{b}_{p v} \in \mathbf{R}^{n \times 1}, \mathbf{c}_{p}^{T} \in \mathbf{R}^{1 \times n}$. Introducing the extended state vector:

$$
\mathbf{x}=\left[\begin{array}{ll}
\mathbf{x}_{p}^{T} & x_{R}
\end{array}\right]^{T},
$$

the state-space model of $\mathrm{CP}$ and ZEI is:

$$
\begin{aligned}
\dot{\mathbf{x}} & =\mathbf{A} \mathbf{x}+\mathbf{b} u+\mathbf{b}_{v} v+\mathbf{b}_{w} w \\
y & =\mathbf{c}^{T} \mathbf{x}
\end{aligned}
$$

with the matrices:

$$
\mathbf{A}=\left[\begin{array}{cc}
\mathbf{A}_{p} & \mathbf{0} \\
-\left(1 / T_{i}\right) \mathbf{c}_{p}^{T} & 0
\end{array}\right], \mathbf{b}=\left[\begin{array}{c}
\mathbf{b}_{p} \\
0
\end{array}\right], \mathbf{b}_{v}=\left[\begin{array}{c}
\mathbf{b}_{p v} \\
0
\end{array}\right], \mathbf{b}_{w}=\left[\begin{array}{c}
\mathbf{0} \\
1 / T_{i}
\end{array}\right], \mathbf{c}^{T}=\left[\begin{array}{ll}
\mathbf{c}_{p}^{T} & 0
\end{array}\right] .
$$

The variable structure control law specific to SMC is of relay type:

$$
u=u_{0} \operatorname{sgn}(g(\mathbf{x})), g(\mathbf{x})=-\mathbf{k}^{T} \mathbf{x}+k_{w} w, \mathbf{k}^{T}=\left[\begin{array}{ll}
\mathbf{k}_{p}^{T} & -k_{R}
\end{array}\right],
$$

where the matrix $\mathbf{k}^{T}$ characterizes the switching hyper-plane and $u_{0}=$ const $>0$ is the absolute value of the control signal. The analysis of the control system in sliding mode is supported by the equivalent control method [60] resulting in the state-space equations of the control system in sliding mode:

$$
\dot{\mathbf{x}}=\mathbf{A}^{s} \mathbf{x}+\mathbf{b}_{v}^{s} v+\mathbf{b}_{w}^{s} w+\mathbf{b}_{\dot{w}}^{s} \dot{w}
$$

with the matrices:

$$
\begin{aligned}
\mathbf{A}^{s} & =\left[\begin{array}{c}
\mathbf{M}_{p} \mathbf{A}_{p}-\left[k_{R} /\left(T_{i} \mathbf{k}_{p}^{T} \mathbf{b}_{p}\right)\right] \mathbf{b}_{p} \mathbf{c}_{p}^{T} \\
-\left(1 / T_{i}\right) \mathbf{c}_{p}^{T} \\
0
\end{array}\right], \mathbf{b}_{v}^{s}=\left[\begin{array}{c}
\mathbf{M}_{p} \mathbf{b}_{p v} \\
0
\end{array}\right], \mathbf{M}_{p}=\mathbf{I}-\left[1 /\left(\mathbf{k}_{p}^{T} \mathbf{b}_{p}\right)\right] \mathbf{b}_{p} \mathbf{k}_{p}^{T}, \\
\mathbf{b}_{w}^{s} & =\left[\begin{array}{c}
{\left[k_{R} /\left(T_{i} \mathbf{k}_{p}^{T} \mathbf{b}_{p}\right)\right] \mathbf{b}_{p}} \\
1 / T_{i}
\end{array}\right], \mathbf{b}_{\dot{w}}^{s}=\left[\begin{array}{c}
k_{w} /\left(\mathbf{k}_{p}^{T} \mathbf{b}_{p}\right) \\
0
\end{array}\right],
\end{aligned}
$$


and $\mathbf{I}$ is the $n^{\text {th }}$ order identity matrix. Equation (6) does not highlight the reaching mode, but its effect can be highlighted by the proper modification of the initial conditions. The sliding mode existence condition involves the equivalent control signal $u_{e q}$ :

$$
\left|u_{e q}\right|<u_{0}, u_{e q}=\left[1 /\left(\mathbf{k}_{p}^{T} \mathbf{b}_{p}\right)\right] \cdot\left[k_{R} x_{R}-\mathbf{k}_{p}^{T}\left(\mathbf{A}_{p} \mathbf{x}_{p}+\mathbf{b}_{p v} v\right)+k_{w} \dot{w}\right] .
$$

All above equations specific to SMC correspond to the case of ZEI that operates in its linear operating mode, i.e. the ZEI is not in saturation:

$$
x_{R L}=x_{R} .
$$

It is very convenient to use equation (6) in the analysis and design of the SMC as it is linear and it characterizes with an acceptable accuracy the behavior of a nonlinear control system (the sliding mode one). Similar models for the FC will be presented as follows.

The rule base of the continuous-time dynamic Takagi-Sugeno (T-S) fuzzy model of $\mathrm{P}$ consists of $n_{R}$ rules, $R^{i}, i=1 \ldots n_{R}$. Each rule is assigned to the following continuous-time state-space model in its consequent, namely to a local linear model of P:

$$
\begin{aligned}
\dot{\mathbf{x}}_{p} & =\mathbf{A}_{p i} \mathbf{x}_{p}+\mathbf{b}_{p i} u, \\
y & =\mathbf{c}_{p i}^{T} \mathbf{x}_{p}, i=1 \ldots n_{R},
\end{aligned}
$$

where $\mathbf{A}_{p i} \in \mathbf{R}^{n \times n}, \mathbf{b}_{p i} \in \mathbf{R}^{n \times 1}, \mathbf{c}_{p i}^{T} \in \mathbf{R}^{1 \times n}$, and the disturbance input is omitted for simplicity. The complete rule base of the continuous-time dynamic T-S fuzzy model of $\mathrm{P}$ is:

$$
\begin{aligned}
& R^{i}: \operatorname{IF} z_{1} \operatorname{IS} L T_{z_{1}}^{i} \text { AND } z_{2} \text { IS } L T_{z_{2}}^{i} \text { AND } \ldots \text { AND } z_{m} \text { IS } L T_{z_{m}}^{i} \\
& \operatorname{THEN}\left\{\begin{array}{c}
\dot{\mathbf{x}}_{p}=\mathbf{A}_{p i} \mathbf{x}_{p}+\mathbf{b}_{p i} u \\
y=\mathbf{c}_{p i}^{T} \mathbf{x}_{p}
\end{array}, i=1 \ldots n_{R},\right.
\end{aligned}
$$

where $\mathbf{z}=\left[\begin{array}{llll}z_{1} & z_{2} & \ldots & z_{m}\end{array}\right]^{T}$ is the scheduling vector, i.e., the input vector, which contains the measurable variables of $\mathrm{P}, z_{k}, k=1 \ldots m$, and $L T_{z_{k}}^{i}$ are the input linguistic terms with the input membership functions $\mu_{z_{k}}^{i}\left(z_{k}\right)$.

Using the SUM and PROD operators in the inference engine and the weighted average defuzzification method, the firing strengths (of the rules) are:

$$
w_{i}(\mathbf{z})=\prod_{k=1}^{m} \mu_{z_{k}}^{i}\left(z_{k}\right), i=1 \ldots n_{R}
$$

the normalized firing strengths are:

$$
h_{i}(\mathbf{z})=w_{i}(\mathbf{z}) /\left[\sum_{i=1}^{n_{R}} w_{i}(\mathbf{z})\right], i=1 \ldots n_{R},
$$

and the continuous T-S fuzzy model of $\mathrm{P}$ is expressed in the state-space form:

$$
\begin{aligned}
& \dot{\mathbf{x}}_{p}=\sum_{i=1}^{n_{R}}\left[h_{i}(\mathbf{z})\left(\mathbf{A}_{p i} \mathbf{x}_{p}+\mathbf{b}_{p i} u\right)\right], \\
& y=\sum_{i=1}^{n_{R}}\left[h_{i}(\mathbf{z}) \mathbf{c}_{p i}^{T} \mathbf{x}_{p}\right] .
\end{aligned}
$$

In parallel distributed compensation (PDC) the structure of the FC model matches the structure of the fuzzy model of $\mathrm{P}$ given in (11). Considering the absence of the blocks $\mathrm{RB}$ and ZEI, the PDC controller for the system (11) is: 


$$
u=-\sum_{i=1}^{n_{R}}\left[h_{i}(\mathbf{z}) \mathbf{f}_{i}^{T} \mathbf{x}_{p}\right]
$$

and the goal of $\mathrm{FC}$ design is to obtain the gain matrices $\mathbf{f}_{i}^{T}, i=1 \ldots n_{R}, \mathbf{f}_{i}^{T} \in \mathbf{R}^{1 \times n}$, of the nonlinear state-feedback control law (15) such that the closed-loop system is stable and eventually robust. As outlined in [61], many design problems derive the least conservative conditions related to the condition:

$$
\sum_{i=1}^{n_{R}} \sum_{j=1}^{n_{R}}\left[h_{i}(\mathbf{z}) h_{j}(\mathbf{z}) \boldsymbol{\Gamma}_{i j}\right]<0, \boldsymbol{\Gamma}_{i j}=\boldsymbol{\Gamma}_{i j}{ }^{T} .
$$

Considering the fuzzy control system structure according to Figure 1, the control law of the FC given in (15) is modified as follows in the specific case of ZEI that operates in its linear operating mode:

$$
u=k_{w} w+k_{R} x_{R}-\sum_{i=1}^{n_{R}}\left[h_{i}(\mathbf{z}) \mathbf{f}_{i}^{T} \mathbf{x}_{p}\right] .
$$

Using (2), (17) and Figure 1 in (14), the state-space equations of the fuzzy control system are:

$$
\dot{\mathbf{x}}=\mathbf{A}^{s} \mathbf{x}+\mathbf{b}_{w}^{s} w
$$

with the matrices:

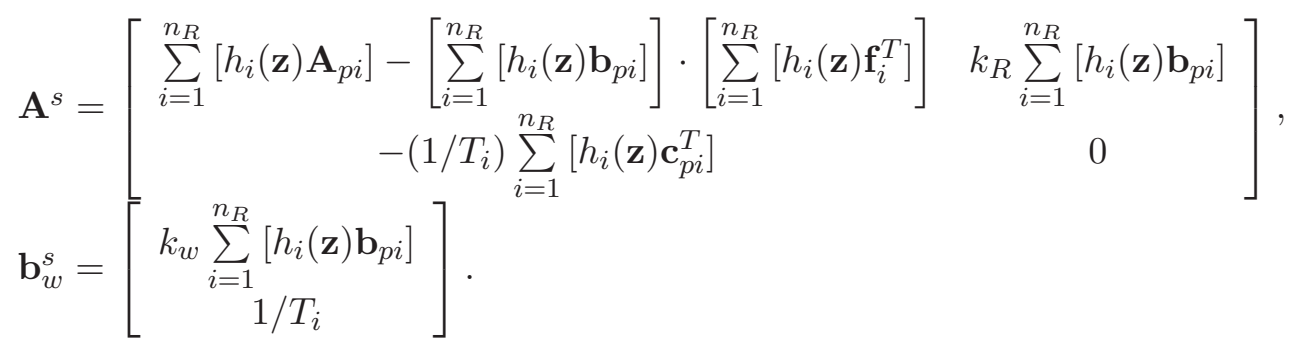

The models (6) (of the sliding mode control system) and (18) (of the fuzzy control system) are similar. Moreover, the gain matrices $\mathbf{f}_{i}^{T}$ of $\mathrm{FC}$ are similar to the gain matrix $\mathbf{k}_{p}^{T}$ of $\mathrm{SMC}$ (illustrated in Figure 1). This justifies the unified treatment of anti-windup techniques for fuzzy and sliding mode controllers. However, sliding mode and fuzzy control systems have different structures; although the fuzzy control system is more complicated, it is not constrained to enter the sliding mode related to the sliding mode existence condition.

If ZEI enters saturation, i.e.:

$$
x_{R L}=x_{R \lim }, x_{R \lim } \in\left\{-x_{L}, x_{L}\right\},
$$

the updated expression of the switching variable is:

$$
g\left(\mathbf{x}_{p}\right)=-\mathbf{k}_{p}^{T} \mathbf{x}_{p}+k_{w} w+k_{R} x_{R \lim },
$$

and the equivalent control method leads to the updated equivalent control signal:

$$
u_{e q}=\left[1 /\left(\mathbf{k}_{p}^{T} \mathbf{b}_{p}\right)\right] \cdot\left[-\mathbf{k}_{p}^{T}\left(\mathbf{A}_{p} \mathbf{x}_{p}+\mathbf{b}_{p v} v\right)+k_{w} \dot{w}\right],
$$

and to the updated state-space equations of $\mathrm{P}$ in sliding mode:

$$
\dot{\mathbf{x}}_{p}=\mathbf{A}_{p}^{s} \mathbf{x}_{p}+\mathbf{b}_{p v}^{s} v+\mathbf{b}_{p \dot{w}}^{s} \dot{w}
$$


with the matrices:

$$
\mathbf{A}_{p}^{s}=\mathbf{M}_{p} \mathbf{A}_{p}, \mathbf{b}_{p v}^{s}=\mathbf{M}_{p} \mathbf{b}_{p v}, \mathbf{b}_{p \dot{w}}^{s}=\left[k_{w} /\left(\mathbf{k}_{p}^{T} \mathbf{b}_{p v}\right)\right] \mathbf{b}_{p} .
$$

Hence, at least one negative effect on control system behavior can be observed when the saturation of the ZEI occurs or when the integrator output is maintained in saturation/outside the limits on a too large time interval. This consists in the difficult fulfillment of the sliding mode existence condition due to the different expressions of $u_{e q}$ in (8) and (22). Therefore, anti-windup techniques are necessary not just to get ZEI out of saturation, but just to avoid exaggerate exceeds of limitation.

\section{Back-Calculation and Tracking Anti-Windup Scheme}

The state-space equation of I that belongs to ZEI is:

$$
\dot{x}_{R}=\left(1 / T_{i}\right) e .
$$

Equation (25) is also kept in the presence of windup, but with the substitution of $e$ with another I input, $e_{L}$, chosen such that to keep ZEI in saturation, i.e., (9) is applied, therefore:

$$
\dot{x}_{R L}=\left(1 / T_{i}\right) e_{L} .
$$

Equation (25) holds in the absence of windup, and equation (26) corresponds to the presence of windup. Subtracting (26) from (25) results in:

$$
e_{L}=e-T_{i}\left(\dot{x}_{R}-\dot{x}_{R L}\right) .
$$

The structure of ZEI with back-calculation and tracking anti-windup scheme is built using (27) and given in Figure 2. BCT in Figure 2 represents the back-calculation and tracking block, with pure derivative character, modeled by the transfer function:

$$
H_{B C T}(s)=T_{i} s
$$

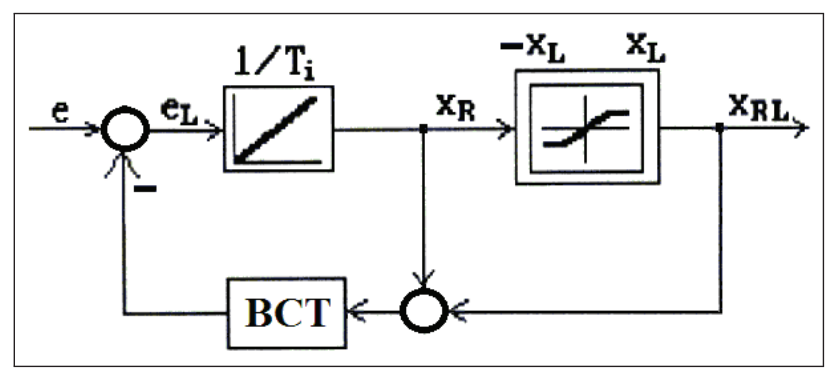

Figure 2: Unified structure of ZEI with back-calculation and tracking anti-windup scheme.

The proposed anti-windup technique has a shortcoming, namely it does not operate if $x_{R}$ enters saturation, and it is constant, or if the difference $\left(x_{R}-x_{R L}\right)$ is constant. Therefore, the modified BCT block (MBCT) is of lead-lag type with the following transfer function:

$$
H_{M B C T}(s)=\left(T_{i} s+k_{A W}\right) /\left(1+T_{A W} s\right),
$$

where the time constant $T_{A W}$ (a small value) is necessary in order to make possible the implementation of MBCT. The anti-windup tracking gain $k_{A W}$ can take any positive value. However, an as small as possible value of $k_{A W}$ is recommended because: (i) the strong feedback derivative action already determines the integrator to stay very close to the saturation limit, (ii) a large value of $k_{A W}$ could lead to stability problems investigated in [62]. 


\section{Position Control Application. Simulation Results}

An example of nonlinear electro-hydraulic system [63] is taken into consideration in order to illustrate the advantages of the proposed back-calculation and tracking anti-windup scheme in the context of state feedback sliding mode control. The simplified structure of the electrohydraulic system meant for position $(y)$ control is presented in Figure 3. The parameters of $\mathrm{P}$ are: $g_{0}=0.0625, T_{i 1}=0.002 \mathrm{~s}, T_{i 2}=0.065 \mathrm{~s}, x_{L}=0.5$.

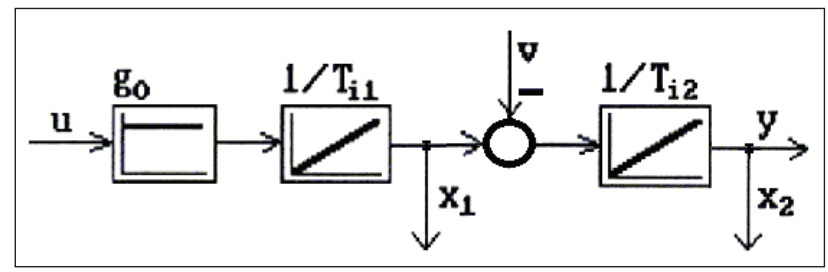

Figure 3: Simplified structure of P.

The design of the SMC is performed according to [59], but for $n=2$, and the following values of controller parameters are obtained: $k_{x 1}=1, k_{x 2}=0.13, \mathbf{k}_{p}^{T}=\left[\begin{array}{ll}k_{x 1} & k_{x 2}\end{array}\right]=\left[\begin{array}{ll}1 & 0.13\end{array}\right]$, $k_{w}=0.13, k_{R}=32.5, T_{i}=0.1 \mathrm{~s}, u_{0}=15$. The overall control system is referred to as electrohydraulic servo-system.

The designed sliding mode control system was tested with respect to the modifications of $w$ using the nonlinear model of P. Figure 4 gives the control system response (the control system output $y$ with continuous line, $w$ with dash dotted line, $x_{R L}$ with continuous line) without limitations imposed to ZEI. Figure 4 shows that $y$ tracks the imposed $w$. Figure 5 gives the

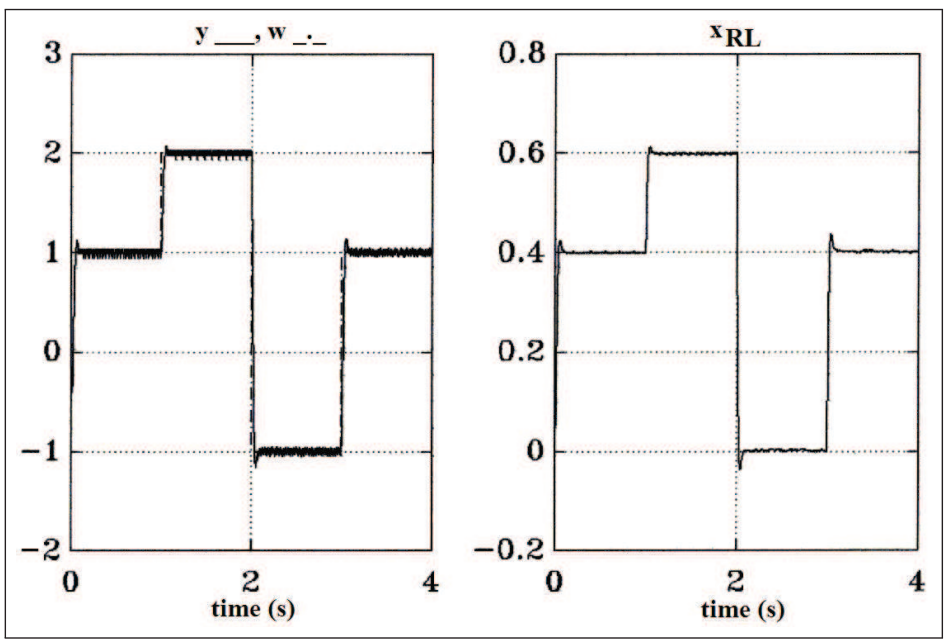

Figure 4: Control system response without limitations.

control system response without anti-windup technique. The harmful effect of the limitation is illustrated by the fact that $y$ does not track anymore $w$, and $x_{R}$ stays during a relatively long time period in limitation within the time interval $[1 \mathrm{~s}, 3 \mathrm{~s}]$.

Figure 6 gives the control system response with classical back-calculation and tracking antiwindup scheme using the same $w$ and conditions as in Figure 4. The control system performance is improved in comparison with the case without back-calculation and tracking anti-windup scheme.

Figure 7 gives the control system response that incorporates the proposed modified backcalculation and tracking anti-windup scheme using the same $w$ and conditions as in Figure 4, and 


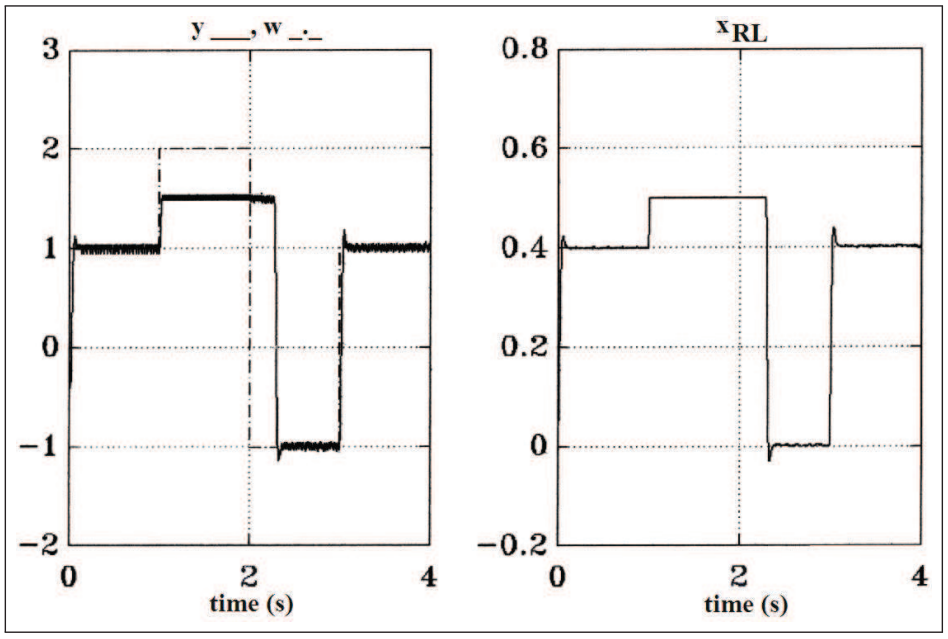

Figure 5: Control system response without BCT.

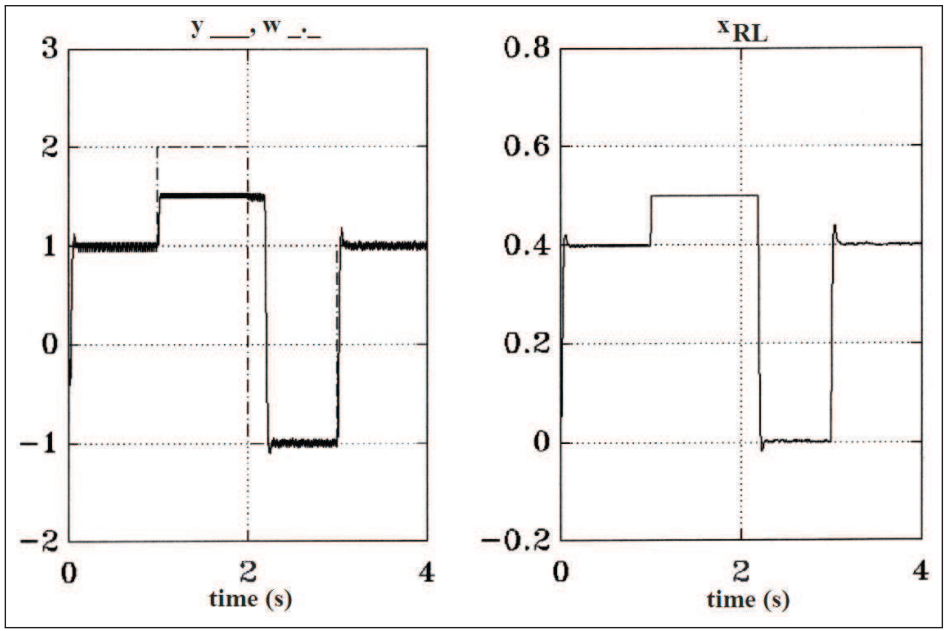

Figure 6: Control system response with BCT.

for $k_{A W}=0.02$ and $T_{A W}=0.01 \mathrm{~s}$. Figure 7 shows the control system performance improvement compared to all previous cases. One relatively minor shortcoming concerns the slightly larger effect of the chattering phenomenon.

\section{Conclusions}

The paper has proposed an approach to the unified treatment of anti-windup in fuzzy and sliding mode controllers. The unified models of fuzzy control systems and sliding mode control systems have been suggested.

An analysis of the possibility to apply the back-calculation and tracking anti-windup scheme to the zero error integrator belonging to a state feedback sliding mode controller has been carried out. A modified back-calculation and tracking anti-windup scheme applicable to these controller structures has been suggested.

The future work will be dedicated to the discrete time formulation of the controllers and of the anti-windup schemes and to the stability analysis because the control systems stability can be affected or not by windup. The parameters of the anti-windup schemes will be tuned by 


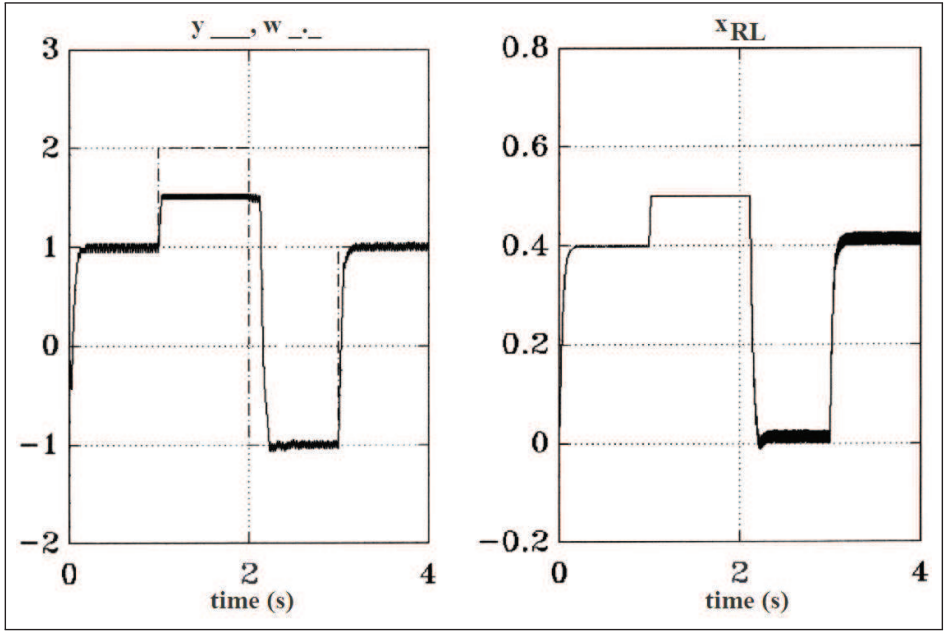

Figure 7: Control system response with MBCT.

several optimization algorithms in the context of appropriate optimization problems.

\section{Acknowledgments}

This work was supported by a grant of the Romanian National Authority for Scientific Research, CNCS - UEFISCDI, project number PN-II-ID-PCE-2011-3-0109, by a grant from the Partnerships in priority areas - PN II program of the Romanian National Authority for Scientific Research ANCS, CNDI - UEFISCDI, project number PN-II-PT-PCCA-2011-3.2-0732, by grants from the Partnerships in priority areas - PN II program of the Romanian Ministry of Education and Research (MEdC) - the Executive Agency for Higher Education, Research, Development and Innovation Funding (UEFISCDI), project numbers PN-II-PT-PCCA-2013-4-0544 and PN-II-PT-PCCA-2013-4-0070, and by a grant from the NSERC of Canada.

\section{Bibliography}

[1] Bohn, C.; Atherton, D. P. (1995); An analysis package comparing PID anti-windup strategies, IEEE Control Systems Magazine, 15(2):34-40.

[2] Peng, Y.; Vrančić, D.; Hanus, R.; Weller, S. S. R. (1998); Anti-windup designs for multivariable controllers, Automatica, 34(12):1559-1565.

[3] Tharayil, M.; Alleyne, A. (2002); A generalized PID error governing scheme for SMART/SBLI control, Proceedings of 2002 American Control Conference, Anchorage, AK, USA, 1:346-351.

[4] Åström, K. J.; Hägglund, T. (2006); Advanced PID Control, Instrument Society of America, Research Triangle Park, NC.

[5] Wu, X.; Lin, Z. (2012); On immediate, delayed and anticipatory activation of anti-windup mechanism: Static anti-windup case, IEEE Transactions on Automatic Control, 57(3):771777.

[6] Fišer, J.; Šulc, B. (2001); Sliding mode control design with anti wind-up, Proceedings of XXVI. ASR'2001 Seminar, Instruments and Control, Ostrava, Czech Republic, Paper ID $17: 1-8$ 
[7] Herrmann, G.; Turner, M. C.; Postlethwaite, I; Guo G. (2004); Practical implementation of a novel anti-windup scheme in a HDD-dual-stage servo-system, IEEE/ASME Transactions on Mechatronics, 9(3):580-592.

[8] Kanamori, M.; Iwagami, K. (2014); Novel anti-windup PID controller design under holonomic endpoint constraints for Euler-Lagrange systems with actuator saturation, Preprints of $19^{\text {th }}$ IFAC World Congress, Cape Town, South Africa, pp. 9321-9326.

[9] Chiang, H.-H.; Hsu, K.-C.; Li I.-H. (2015); Optimized adaptive motion control through an SoPC implementation for linear induction motor drives, IEEE/ASME Transactions on Mechatronics, 20(1):348-360.

[10] Septanto, H.; Syaichu-Rohman, A.; Mahayana, D. (2011); Static anti-windup compensator design of linear sliding mode control for input saturated systems, Proceedings of 2011 International Conference on Electrical Engineering and Informatics, Bandung, Indonesia, pp. $1-4$.

[11] Yokoyama, M.; Kim, G.-N.; Tsuchiya, M. (2012); Integral sliding mode control with antiwindup compensation and its application to a power assist system, Journal of Vibration and Control, 16(4):503-512.

[12] Lee, J. M.; Park, S. H.; Kim, J. S. (2013); Design and experimental evaluation of a robust position controller for an electrohydrostatic actuator using adaptive antiwindup sliding mode scheme, The Scientific World Journal, Vol. 2013, Article ID 590708, pp. 1-16.

[13] Zaafouri, C.; Garcia, G. (2013); Comparative study of the saturated sliding mode and antiwindup controllers, Proceedings of 2013 International Conference on Electrical Engineering and Software Applications, Hammamet, Tunisia, pp. 1-6.

[14] Preitl, S.; Precup, R.-E. (1995); On the opportunity of ARW measures in fuzzy control, in: Real World Applications of Intelligent Technologies, H.-J. Zimmermann, M. G. Negoita, D. Dascalu, Eds., Editura Academiei Romane, Bucharest, pp. 149-153.

[15] Zhang, T.; Feng, G.; Liu, H.; Lu, J. (2009); Piecewise fuzzy anti-windup dynamic output feedback control of nonlinear processes with amplitude and rate actuator saturations, IEEE Transactions on Fuzzy Systems, 17(2):253-264 .

[16] Ting, C.-S.; Chang, Y.-N. (2011); Robust anti-windup controller design of time-delay fuzzy systems with actuator saturations, Information Sciences, 181(15):3225-3245.

[17] Precup, R.-E.; Preitl, S. (1997); Popov-type stability analysis method for fuzzy control systems, Proceedings of Fifth European Congress on Intelligent Technologies and Soft Computing, Aachen, Germany, (2):1306-1310.

[18] Precup, R.-E.; Preitl, S. (1999); Fuzzy Controllers, Editura Orizonturi Universitare, Timişoara, 1999.

[19] Precup, R.-E.; Preitl, S.; Balas, M.; Balas, V. (2004); Fuzzy controllers for tire slip control in anti-lock braking systems, Proceedings of IEEE International Conference on Fuzzy Systems, Budapest, Hungary, (3):1317-1322.

[20] Precup, R.-E.; Preitl, S. (2006); Stability and sensitivity analysis of fuzzy control systems. Mechatronics applications, Acta Polytechnica Hungarica, 3(1):61-76. 
[21] Tomescu, M. L.; Preitl, S.; Precup, R.-E.; Tar, J. K. (2007); Stability analysis method for fuzzy control systems dedicated controlling nonlinear processes, Acta Polytechnica Hungarica, $4(3): 127-141$.

[22] Precup, R.-E.; Tomescu, M. L.; Preitl, S. (2009); Fuzzy logic control system stability analysis based on Lyapunov's direct method, International Journal of Computers, Communications E3 Control, 4(4):415-426.

[23] Precup, R.-E.; Tomescu, M. L.; Radac, M.-B.; Petriu, E. M.; Preitl, S.; Dragos, C.-A. (2012); Iterative performance improvement of fuzzy control systems for three tank systems, Expert Systems with Applications, 39(9):8288-8299.

[24] Precup, R.-E.; Radac, M.-B.; Tomescu, M. L.; Petriu, E. M.; Preitl, S. (2013); Stable and convergent iterative feedback tuning of fuzzy controllers for discrete-time SISO systems, Expert Systems with Applications, 40(1):188-199.

[25] Precup, R.-E.; David, R.-C.; Petriu, E. M.; Radac, M.-B.; Preitl, S. (2014); Adaptive GSA-based optimal tuning of PI controlled servo systems with reduced process parametric sensitivity, robust stability and controller robustness, IEEE Transactions on Cybernetics, 44(11):1997-2009.

[26] Zadeh, L. A. (1974); Fuzzy logic and its application to approximate reasoning, Proceedings of IFIP Congress 74, Stockholm, Sweden, pp. 591-594.

[27] Zadeh, L. A. (1994); Fuzzy logic: issues, contentions and perspectives, Proceedings of IEEE International Conference on Acoustics, Speech and Signal Processing ICASSP94, Adelaide, SA, Australia, pp. 183-184.

[28] Zadeh, L. A. (2013); Stochastic finite-state systems in control theory, Information Sciences, 251:1-9.

[29] Mitroi, F. C.; Minculete, N. (2013); Mathematical inequalities for biparametric extended information measures, Journal of Mathematical Inequalities, 7(1):63-71.

[30] Nădăban, S.; Dzitac, I, (2014); Atomic decompositions of fuzzy normed linear spaces for wavelet applications, Informatica, 25(4):643-662.

[31] Gál, L.; Lovassy, R.; Rudas, I. J.; Kóczy, L. T. (2014); Learning the optimal parameter of the Hamacher t-norm applied for fuzzy-rule-based model extraction, Neural Computing and Applications, 24(1):133-142.

[32] Nădăban, S. (2015); Fuzzy Euclidean normed spaces for data mining applications, International Journal of Computers, Communications \& Control, 10(1):70-77.

[33] Nădăban, S. (2014); Fuzzy pseudo-norms and fuzzy F-spaces, Fuzzy Sets and Systems, DOI: 10.1016/j.fss.2014.12.010.

[34] Nădăban, S.; Dzitac, I (2014); Special Types of Fuzzy Relations, Procedia Computer Science, 31C:552-557.

[35] Škrjanc, I; Blažič, S.; Agamennoni, O. E. (2005); Interval fuzzy model identification using $l_{\infty}$-norm, IEEE Transactions on Fuzzy Systems, 13(5):561-568. 
[36] Johanyćk, Z.C. (2010); Survey on five fuzzy inference-based student evaluation methods, in: Computational Intelligence in Engineering, I. J. Rudas, J. Fodor, J. Kacprzyk, Eds., Studies in Computational Intelligence, Springer-Verlag, Berlin, Heidelberg, Vol. 313, pp. 219-228.

[37] Vaščák, J. (2010); Approaches in adaptation of fuzzy cognitive maps for navigation purposes, Proceedings of $8^{\text {th }}$ International Symposium on Applied Machine Intelligence and Informatics, Heržany, Slovakia, pp. 31-36, 2010.

[38] Linda, O.; Manic, M. (2011); Interval type-2 fuzzy voter design for fault tolerant systems, Information Sciences, 181(14):2933-2950.

[39] Dragos, C.-A.; Precup, R.-E.; Tomescu, M. L.; Preitl, S.; Petriu, E. M.; Radac, M.-B. (2013); An approach to fuzzy modeling of electromagnetic actuated clutch systems, International Journal of Computers, Communications \& Control, 8(3):395-406.

[40] Teodorescu, H.-N. L. (2013); On the characteristic functions of fuzzy systems, International Journal of Computers, Communications \& Control, 8(3):469-476.

[41] Jafarian, A. ( 2014); New artificial intelligence approach for solving fuzzy polynomial equations, International Journal of Artificial Intelligence, 12(2):57-74.

[42] Baranyi, P.; Tikk, D.; Yam, Y.; Patton, R. J. (2003); From differential equations to PDC controller design via numerical transformation, Computers in Industry, 51(3):281-297.

[43] Precup, R.-E.; Preitl, S.; Radac, M.-B.; Petriu, E. M.; Dragos, C.-A.; Tar, J. K. (2011); Experiment-based teaching in advanced control engineering, IEEE Transactions on Education, 54(3):345-355.

[44] Precup, R.-E.; Dragos, C.-A.; Preitl, S.; Radac, M.-B.; Petriu, E. M. (2012); Novel tensor product models for automatic transmission system control, IEEE Systems Journal, 6(3):488498.

[45] Angelov, P.; Yager, R. (2013); Density-based averaging - A new operator for data fusion, Information Systems, 222:163-174.

[46] Bălănică, V.; Dumitrache, I.; Preziosi, L. (2013); Breast cancer diagnosis based on spiculation feature and neural network techniques, International Journal of Computers, Communications \& Control, 8(3):354-365.

[47] Osaba, E.; Diaz, F.; Onieva, E.; Carballedo, R.; Perallos, A. (2014); AMCPA: A population metaheuristic with adaptive crossover probability and multi-crossover mechanism for solving combinatorial optimization problems, International Journal of Artificial Intelligence, 12(2):123.

[48] Popescu, D.; Cirstoiu, S. (2014); A simulator for the multi-model control of Diesel engines, Studies in Informatics and Control, 23(4):381-386.

[49] Yu, X.; Kaynak, O. (2009); Sliding-mode control with soft computing: A survey, IEEE Transactions on Industrial Electronics, 56(9):3275-3285.

[50] Antić, D.; Milojković, M.; Jovanović, Z.; Nikolić, S. (2010); Optimal design of the fuzzy sliding mode control for a DC servo drive, Strojniški vestnik - Journal of Mechanical Engineering, 56(7-8):455-463. 
[51] Al-Hadithi, B. M.; Barragán, A. J.; Andújar, J. M.;Jiménez, A. (2013); Variable structure control with chattering elimination and guaranteed stability for a generalized T-S model, Applied Soft Computing, 13(12):4802-4812.

[52] Milosavljević, C.; Perunicić-Drazenović, B. Veselić, B. (2013); Discrete-time velocity servo system design using sliding mode control approach with disturbance compensation, IEEE Transactions on Industrial Informatics, 9(2):920-927.

[53] Liu, Z.; Su, H.; Pa, S. (2014); A new adaptive sliding mode control of uncertain nonlinear systems, Asian Journal of Control,16(1):198-208.

[54] Filip, F.-G.; Leiviskä, K. (2009); Large-scale complex systems, in: Springer Handbook of Automation, S. Y. Nof, Ed., Springer-Verlag, Berlin, Heidelberg, pp. 619-638.

[55] Precup, R.-E.; David, R.-C.; Petriu, E. M.; Preitl, S.; Paul, A. S. (2011); Gravitational search algorithm-based tuning of fuzzy control systems with a reduced parametric sensitivity, in: Soft Computing in Industrial Applications, A. Gaspar-Cunha, R. Takahashi, G. Schaefer, L. Costa, Eds., Springer-Verlag, Berlin, Heidelberg, Advances in Intelligent and Soft Computing, Vol. 96, pp. 141-150.

[56] Penedo, F.; Haber, R. E.; Gajate, A.; del Toro, R. M. (2012); Hybrid incremental modeling based on least squares and fuzzy K-NN for monitoring tool wear in turning processes, IEEE Transactions on Industrial Informatics, 8(4):811-818.

[57] Barchinezhad, S.; Eftekhari, M. (2014); A new fuzzy and correlation based feature selection method for multiclass problems, International Journal of Artificial Intelligence, 12(2):24-41.

[58] Astudillo, L.; Melin, P.; Castillo, O. (2015); Introduction to an optimization algorithm based on the chemical reactions, Information Sciences, 291:85-95.

[59] Bühler, H. (1986); Réglage par mode de glissement, Presses Polytechniques Romandes, Lausanne.

[60] Utkin, V. I. (1997); Variable structure systems with sliding modes, IEEE Transactions on Automatic Control, AC-22(2):212-222.

[61] Precup, R.-E.; Hellendoorn, H. (2011); A survey on industrial applications of fuzzy control, Computers in Industry, 62(3):213-226.

[62] Preitl, S.; Precup, R.-E. (1993); Anti-Reset-Windup (ARW) structure for speed control of hydrogenerators, Proceedings of CSCS-9 International Conference, Bucharest, Romania, 2:390-397.

[63] Preitl, S. (1986); Aspects concerning the algorithmic design of electro-hydraulic servosystems for speed controllers, Proceedings of CCSITEH National Symposium, Timisoara, Romania, pp. 143-149 (in Romanian). 